\title{
http://jaet.journals.ekb.eg \\ Investigating the Impact of Different Glazing Types on the Energy Performance in Hot Arid Climate Ayman Ragab
}

\author{
Department of Architecture, Faculty of Engineering, Aswan University, Aswan 81542, Egypt. \\ corresponding author: ayman.ragab@aswu.edu.eg
}

\section{ABSTRACT}

This study investigated the effect of different glazing types with various window orientations and Window to Wall Ratio WWR (10\%, and 20\%) on energy consumption in a typical room in an office building located in the hot climatic conditions of Aswan, Egypt. This case study was modelled and evaluated using Design Builder software to attain acceptable environmental performance for the study case while also investigating its impact on the amount of energy required for cooling, lighting, and heating. The research revealed that using an embedded nanogel layer between two layers of argon and two layers of single transparent glazing with (WWR $=10 \%$ ) resulted in a significant reduction in total annual energy use for all directions (North, West, South, and East), saving $3.66 \%, 12.71 \%, 6.51 \%$, and $4.18 \%$ respectively when compared to a single layer of clear glass $(3 \mathrm{~mm})$. Furthermore, the results show that utilizing an integrated nanogel layer between two layers of argon and two layers of single transparent glazing has about the same efficiency as WWR $=10 \%$ when WWR $=20 \%$. The study went into further depth to assist decision-makers by using the Pugh matrix to determine the optimum glazing among the proposed glazing types according to several studied criteria. It was discovered that utilizing an integrated nanogel layer between two layers of argon and two layers of single transparent glazing gave the best outcomes, obtaining a score of 3.54, which was higher than any score for the other proposed glazing types.

Keywords: Energy Efficiency; Nanogel Glazing; Building Orientations; Window to Wall Ratio; Pugh Matrix.

\section{INTRODUCTION}

Egypt's Sustainable Development Vision 2030, published in February 2016, highlighted the country's aims for creating a sustainable energy sector. Egypt's energy industry is the major driver of socio-economic advancement, accounting for around 13\% of the country's current GDP, making economic growth significantly contribute to the country's stability. Therefore, energy conservation in buildings is gaining a lot of attention in Egypt, especially among designers and decision-makers. Because of the fast population growth, which has resulted in increased energy consumption and higher energy prices. Whereas the built environment consumes around $42 \%$ of energy in Egypt, overcoming the high air temperature due to heat waves necessitates increased air conditioners, which produce an increase in energy consumption[1]. In this respect, the government has made many attempts as a response to the energy crises. In 2015, Aswan implemented a new project to rationalize Revised:14 Septamber, 2021, Accepted:6 Novamber , 2021 about $25 \%$ of the energy utilized for street lighting[2] as well as their efforts to reduce energy consumption in governmental buildings.

In hot dry climates, the building envelope leads to a significant amount of heat entering the building. The influence of building envelope features such as walls, windows, and roofs on the energy demand for cooling in buildings has been studied in many studies. Several studies look at the influence of windows on cooling and lighting energy demand since they have such a significant impact on energy consumption when compared to other building envelope elements[3-6]. Mamdooh Alwetaishi[7], study the impact of glazing to wall ratio in different Saudi Arabian microclimate areas. Based on a prior study, the researcher looked at the highest feasible glazing ratios in the region: $5 \%$, $10 \%, 20 \%, 30 \%$, and $40 \%$ out of the exterior wall. According to the research, the south and east orientations are the worst for gaining the most heat in all the locations.

Cesari, et al[8], studied the effects of various window sizes and glazings on heating and cooling energy demands in a hospital patient room to 
determine the energy savings possible by using larger apertures and to determine the most effective glazing types. The energy performance of a base case window with a $25 \%$ Window-to-Wall Ratio (WWR) and a wall-to-ceiling window with a $77 \%$ WWR in rooms facing four different orientations in Bologna, Italy, was investigated. They found that the use of larger windows with suitable glazing can reduce heating and cooling energy consumption.

Yoon et al [9]. conducted a basic study on the features of energy performance based on glazing performance, window area ratio, and internal heat generation while developing office buildings. Increased internal heating value resulted in a small reduction in heating energy while considerably increasing cooling energy demand. Furthermore, the glazing's poor heat transfer coefficient lowered conductive heat loss, increasing energy consumption. Vesna Žegarac Leskovar et al[10]. investigated an architectural design method to establish an ideal proportion of glazing areas in prefabricated timber-frame buildings in terms of energy efficiency, with a particular focus on southoriented glazing surfaces.

When the energy-saving and daylighting features of a building are examined at the same time, selecting window glazing becomes more difficult. Therefore, several studies examined the impact of different glazing types on lighting energy demands. Hee, W. J., et al[11], seeking to figure out how window glazing affects a building's energy and daylighting efficiency. They identified a number of criteria for optimum glazing choices, including thermal properties, optical properties, window sizing, window orientation, employment region, and costs. Impact of different window positions and orientations on energy consumption for lighting in a typical room in an office building is investigated by Neveen Azmy et al. They found that a (WWR 20\%) square north-oriented top aperture with the following proportion (3:1) consumes $25 \%$ less energy than a rectangle window in the lower west-oriented façade. Furthermore, they found that the higher apertures provide the best natural lighting since the light reaches over $60 \%$ of the space[12].

Other studies have looked at utilizing nanomaterials in exterior windows due to their thermal characteristics and visible light transmission[5, 10, 13-18]. Abdelrady, et al [3], looked at the impact of nanogel glazing in windows on residential building energy consumption in New Aswan City, Egypt. They concluded that using an embedded nanogel layer between two layers of argon and two layers of single transparent glass with $(\mathrm{WWR}=10 \%)$ reduced annual energy usage by $26 \%$ when compared to using a single layer of glass. Ihara and Gao[19] investigated the impact of a transparent nanogel granulate glazing system on office building spandrels in three hot climate cities.
The simulations showed that the nanogel might consume less energy than double-glazed facades. Rashwan and Farag[20] studied an office building's reduced energy usage under Aswan weather conditions. They noticed that the high transparent windows lost about $60 \%$ of the energy. In AlDammam, Saudi Arabia, recent studies were conducted in single- and multi-story office buildings. The simulations showed that the nanogel in the windows might reduce energy usage when compared to conventional glass (3mm transparent glazing) [21, 22].

The current research looked at how changing window glazing affects energy consumption for cooling and lighting in an office building in New Aswan City, Egypt, taking into account building orientations. The study's base casing is a $3 \mathrm{~mm}$ glass window. The Design-Builder software was used to simulate energy usage. All the instances studied had a window-to-wall ratio of $10 \%$ or $20 \%$.

\section{MATERIAL AND METHODS}

Previous studies have found that heat transmission via windows has the highest value during the day when compared to the rest of the building envelope[4]. Therefore, this study looked at the effects of different glazing types in different building orientations on the energy demand for cooling and lighting in a standard room in an office building in Aswan, which has a hot, dry climate. In this regard, the analysis proceeded through three major phases. The first phase considered the effect of the glazing types on the energy demand for cooling in a standard room in an office building. The second phase investigated the impact of these glazing types on the energy demand for lighting in the buildings. The third phase is to conduct an overview study of the total energy consumption in the examined room to find the best glazing type from the investigated glazing.

\subsection{Study Area and Model Description}

Egypt is located between latitudes $22^{\circ}$ and $32^{\circ}$ North and longitudes $25^{\circ}$ and $36^{\circ}$ East. Egypt's climate is predominantly hot. According to the Housing and Building Research Centre (HBRC), Egypt has eight major regional climates as shown in Figure 1. Aswan is located in the region of southern Egypt and has a hot, dry climate. Moreover, Aswan city stands around 85 meters above sea level and is 879 kilometers from Cairo, with a governorate area of $34,608 \mathrm{~km}^{2}$. Aswan's climate is hot in the summer and warm in the winter, and it has the characteristics of a continental climate; as the maximum and lowest temperature variations increase over the twenty-four hours, whether in summer or winter. 
Vol.42, No.1. January2023

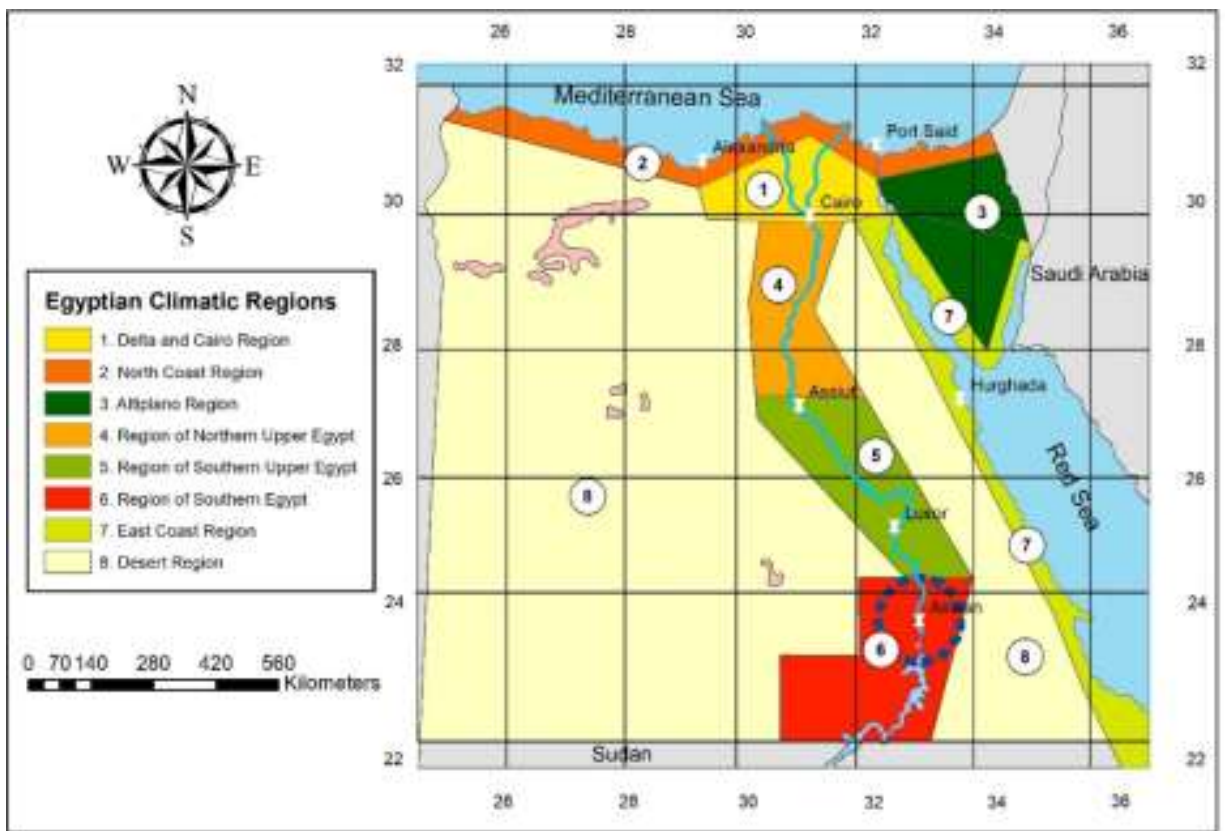

Figure 1. The climatic regions of Egypt[5].

The case study model is an administration office in a multi-story brick building. Figure 2 . depicts the room geometry, which has the following dimensions: $(3.6 \mathrm{~m})$ width, (5.4 m length), and (3.5 $\mathrm{m}$ total height). The wall layers are made up of $0.02 \mathrm{~m}$ external cement plaster, $0.12 \mathrm{~m}$ brick, and $0.02 \mathrm{~m}$ internal cement plaster. The window in the room is only on one side and has a metal frame. The study changes the building orientations while studying the window to wall ratio (WWR) at $10 \%$ and $20 \%$.

Table 1 shows the main characteristics of the external walls, and the fundamental characteristics of the elements utilized, which are placed within the Design-Builder modelling software. Table 2 shows the specification of the study building's simulation hypothesis. Moreover, this space is naturally ventilated except on critical days of the year when air conditioners are used.

Table 1. The main features of the exterior walls.

\begin{tabular}{ccc}
\hline Abbreviation & Wall layers and materials & U-Value $\left(\mathbf{W} / \mathbf{m}^{\mathbf{2}}-\mathbf{K}\right)$ \\
\hline W1 & $20 \mathrm{~mm}$ Cement Plaster $+120 \mathrm{~mm}$ Brick $+20 \mathrm{~mm}$ & 2.434 \\
Cement Plaster & \\
\hline
\end{tabular}


Vol.42, No.1. January2023

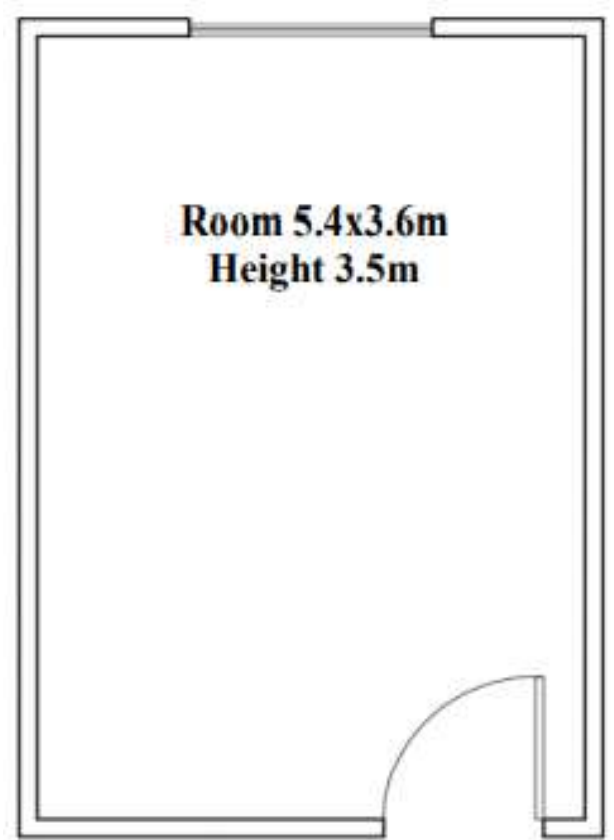

Figure 2. The study model characteristics.

Table 2. Specification of the simulation hypothesis of the study building

\begin{tabular}{cc}
\hline Item & Specification \\
Type & $\begin{array}{c}\text { Standard room in } \\
\text { an office building } \\
\text { Aswan City- Egypt }\end{array}$ \\
Location & $19.44 \mathrm{~m}^{2}$ \\
Floor area & $3.5 \mathrm{~m}$ \\
Floor height & 3 per room \\
Occupancy (Persons) & $10 \%$, and $20 \%$ \\
Window-to-wall ratio & 300 Lux \\
Lighting & 1 split air conditioner \\
HVAC & $25^{\circ} \mathrm{C}$ \\
Cooling setpoint & $18{ }^{\circ} \mathrm{C}$ \\
Heating setpoint & 0.70 \\
Air infiltration (ACH) & $9: 00-17: 00$ \\
\hline
\end{tabular}

\subsection{Glass Specifications}

To assist designers and decision-makers, the performance of various glazing types with various building orientations is quantified and ranked in terms of energy savings for lighting and cooling. The study investigates the effect of six types of glazing on the energy demand for cooling and lighting. The characteristics of the windows as window layers, Solar heat gain coefficient (SHGC), Visible light transmittance, and U-Value are presented in Table 3.

Table 3. Characteristics of the windows

\begin{tabular}{ccccc}
\hline Abbreviation & Window layers and materials & $\begin{array}{c}\text { Solar heat gain } \\
\text { coefficient (SHGC) }\end{array}$ & $\begin{array}{c}\text { Visible light } \\
\text { transmittance }\end{array}$ & $\begin{array}{c}\text { U-Value } \\
\left(\mathbf{W} / \mathbf{m}^{2}-\mathbf{K}\right)\end{array}$ \\
\hline G1 & 3 mm Clear glass & 0.861 & 0.898 & 5.894 \\
G2 & 6 mm Clear glass & 0.819 & 0.881 & 5.778
\end{tabular}




\begin{tabular}{|c|c|c|c|c|}
\hline G3 & $\begin{array}{c}6 \mathrm{~mm} \text { Clear glass }+13 \mathrm{~mm} \text { Air }+6 \\
\text { mm Clear glass }\end{array}$ & 0.703 & 0.781 & 2.665 \\
\hline G4 & $\begin{array}{l}6 \mathrm{~mm} \text { Clear glass }+13 \mathrm{~mm} \text { Argon } \\
+6 \mathrm{~mm} \text { Clear glass }\end{array}$ & 0.704 & 0.781 & 2.511 \\
\hline G5 & $\begin{array}{c}6 \mathrm{~mm} \text { Clear glass }+10 \mathrm{~mm} \text { nanogel } \\
+6 \mathrm{~mm} \text { Clear glass }\end{array}$ & 0.52 & 0.373 & 2.13 \\
\hline G6 & $\begin{array}{c}6 \mathrm{~mm} \text { Clear glass }+13 \mathrm{~mm} \text { Argon } \\
+10 \mathrm{~mm} \text { nanogel }+13 \mathrm{~mm} \text { Argon } \\
+6 \mathrm{~mm} \text { Clear glass }\end{array}$ & 0.35 & 0.3 & 0.45 \\
\hline
\end{tabular}

\subsection{Simulation Processes and Input Weather Data}

The Design-Builder software in its fourth edition (V.4.0.0.105) was used as a model utilizing the dynamic thermal simulation for various glazing types. The study's basic case comprises a single 3 $\mathrm{mm}$ clear glass, which represents the most common type of glazing in Egypt. The building plan was created in $2 \mathrm{D}$ AutoCAD and then exported to the simulation software for testing.

The Design-Builder software includes various (Energy Plus Weather) epw files for Egyptian cities that are more compatible with the US Department of Energy's official website. These epw files are text-based CSV files that include a year's worth of hourly weather variables for the investigated area. To simulate the present climatic conditions in the city, the climate file for Aswan city in the simulation software has been updated with another imported file from the meteorological station (Hobo U30) at Aswan University for the year 2020[3, 4]. Since this EPW file containing weather data cannot be directly updated, it is first converted to a CSV file in order to receive different extracted meteorological data from the weather station. After changing the climatic parameters in a new CSV, the changed CSV is exported to a new EPW that is utilized as input data in Design Builder software.

\section{RESULTS AND DISCUSSION}

The annual energy consumption for cooling and lighting purposes were plotted using the findings from the simulations for the investigated window glazings in the Aswan climate. The energy model was conducted using a window to wall ratio of $(\mathrm{WWR}=10 \%, \mathrm{WWR}=20 \%)$ and varied window orientations to determine how different glazing types affected the building's energy performance. The determined energy saved in all cases was compared to the base case (G1).

\subsection{The effect of window glazing on the energy} demand for cooling.

The simulation results for the various window glazings are shown in Figure $3 \mathrm{a}$, and $\mathrm{b}$. The simulation process was created with window to wall ratio $(\mathrm{WWR}=10)$. For the $\mathrm{WWR}=10 \%$, the $(\mathrm{G} 6)$ window (with nanogel and argon layers) gave the best results compared to other types of windows in terms of annual energy consumption for cooling purposes, and annual energy savings. All building orientations showed an improvement in terms of energy consumption for cooling. For the North, West, South, and East directions, this window saved $15.2 \%, 22 \%, 19 \%$, and $17.4 \%$ of annual energy, respectively, compared to the (G1) window. While the (G5) window (nanogel layer) exhibited annual energy consumption reductions of $8.5 \%, 10 \%, 15 \%$, and $9.6 \%$, respectively, for the North, West, South, and East orientations. These percentages are higher than those for a double-glazed window with an air (G3) or argon (G4) layer in between the glass in all orientations. In terms of annual energy savings, the (G3) and (G4) achieve roughly the same results with $6.6 \%, 5.2 \%, 7 \%$, and $6.4 \%$ for the North, West, South, and East directions, respectively. In all investigated building orientations, the (G2) window (with thicker glass) has a modest effect, saving just $1 \%$ till $2.5 \%$ all over the building orientations compared to the basic case (G1). As a result, the most energy-efficient glazing type among the tested types in terms of cooling energy consumption is (G6), which also had the best performance in the west orientation, reducing the annual energy required for cooling by $445.46 \mathrm{kWh}$ in the west direction which registered the best performance among all directions. While it had the worst performance in the North orientation, reducing the annual energy required for cooling by $278.78 \mathrm{kWh}$.

Figure 4 shows that $\mathrm{WWR}=20 \%$ results are less efficient than WWR $=10 \%$ findings. The amount of heat gained has dramatically increased with higher window-to-wall ratios due to higher thermal transfer by window glazings. Since, temperature differences and solar radiation are the main reasons for increasing the amount of heat transferred by window glazings. While thermal transfer in walls is merely caused by temperature differences. These findings are consistent with previous studies that investigate the relationship between window-to-wall ratio and the total heat transferred through building envelop[23, 24]. In all building orientations, the (G6) window performed the best of all evaluated glass types. When compared to the (G1) window, (G6) saves $12.6 \%, 25.6 \%, 22.3 \%$, and $21 \%$ in the northern, western, southern, and eastern directions, 
respectively. The (G5) window also performed well following (G6). When compared to (G1), (G5) reduces cooling energy consumption by $7.2 \%$, $12.4 \%, 12.8 \%$, and $10.5 \%$ for the northern, western, southern, and eastern orientations, respectively. For all building orientations, (G4) is somewhat more efficient than (G3). While (G2) has the lowest

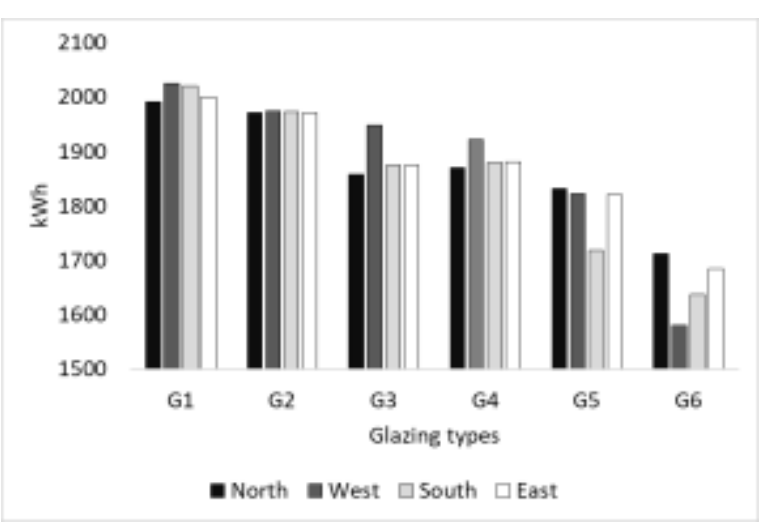

(a) energy consumption performance of the glazing types evaluated when compared to the (G1). Consequently, in terms of cooling energy consumption, the most energyefficient glazing type among the evaluated types is (G6), which also had the highest performance in the west orientation, lowering the annual energy required for cooling by $494.68 \mathrm{kWh}$.

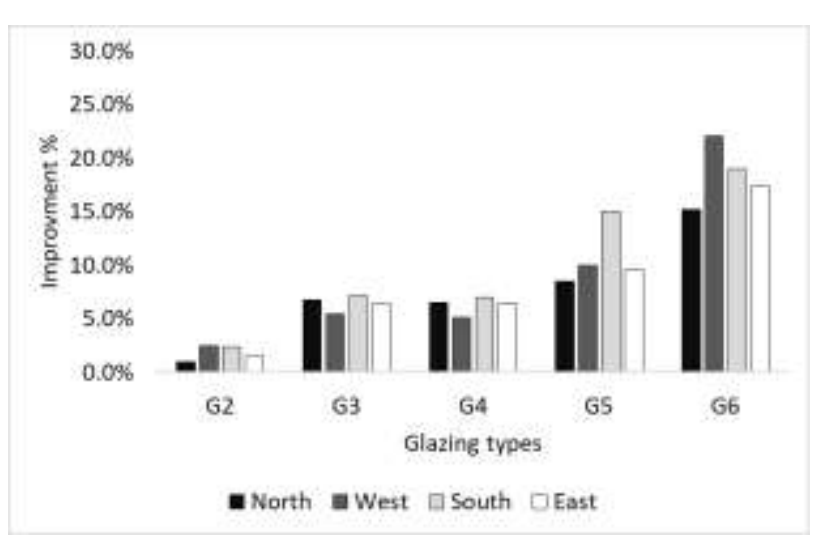

(b) energy savings percentages.

Figure 3. Cooling simulation results for window glazings (WWR=10\%): energy consumption and saving.

The low thermal conductivity of nanogel relative to argon or air allows for the excellent thermal insulation of nanogel-based widows. Nanogel also restricts airflow through small pores. The condensed effect within the nanopores of nanogel caused the embedded air inside the nanopores to have a lower thermal conductivity than

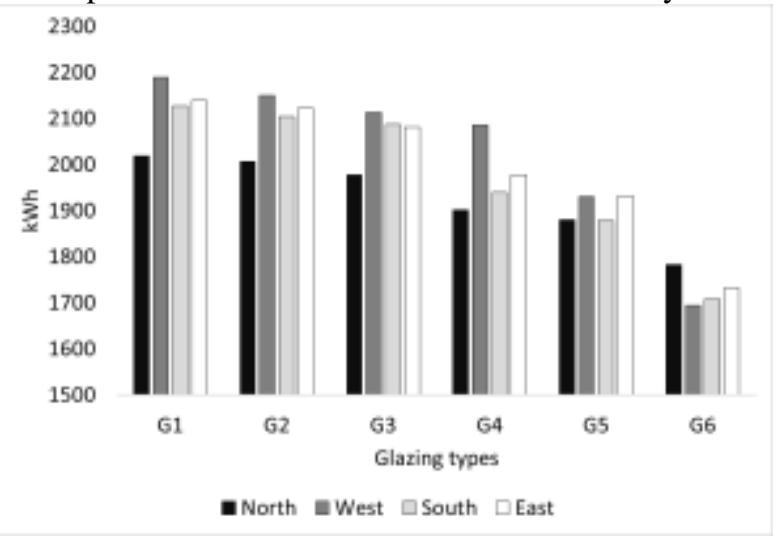

(a) energy consumption free air at ambient pressure. Furthermore, when compared to various types of double-glazed fillers, the nanogel exhibited a reduced heat transmission. This might be because nanogel has a lower solar heat gain coefficient and U-value $\left(0.35\right.$ and $0.45 \mathrm{~W} / \mathrm{m}^{2} \mathrm{~K}$, respectively) than ordinary double glazing $(0.75$ and $\left.2.71 \mathrm{~W} / \mathrm{m}^{2} \mathrm{~K}\right)$.

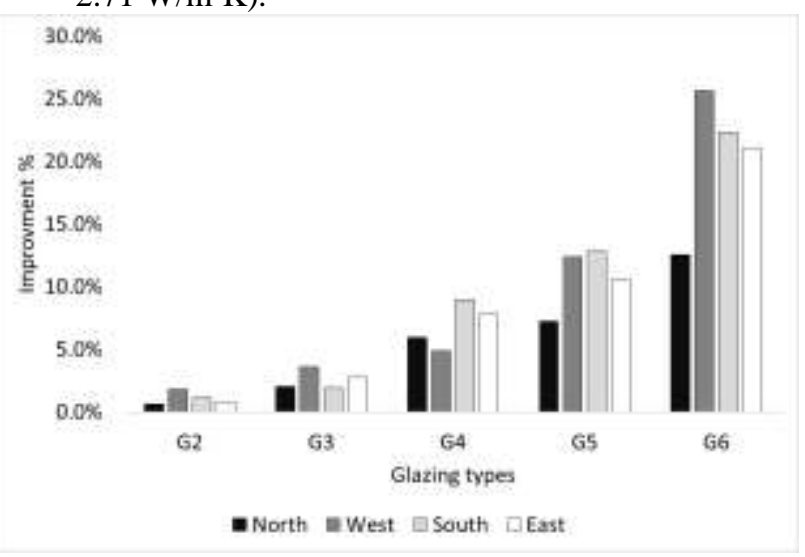

(b) energy savings percentages.

Figure 4. Cooling simulation results for window glazings (WWR=20\%): energy consumption and saving.

3.2. The effect of window glazing on the energy demand for lighting.

The annual energy required for lighting and the annual energy savings of the building with various glazing types is depicted in Figures 5 a, and b. For $\mathrm{WWR}=10 \%$, and $\mathrm{WWR}=20 \%$, the results show an increase in the amount of energy used for lighting purposes in (G6) as compared to (G1). When comparing all cases and investigated orientations, it was discovered that the amount of energy used for lighting purposes has increased in all cases. Almost, the southern and eastern façade use the least amount of energy for lighting each year. It might be due to the sun's movement in the sky's dome, which causes the sun rays to fall on these facades during working hours. For the WWR $=20 \%$, it was observed that (G6) consumed $451.52 \mathrm{kWh}$ with an increasing amount of about $238.59 \mathrm{kWh}$ compared to (G1) in the northern direction. Furthermore, in the West, South, and East directions, it used $348.62 \mathrm{kWh}$, 
$339.19 \mathrm{kWh}$, and $379.68 \mathrm{kWh}$, respectively. In general, lighting energy requirements in the eastern and southern orientations do not exceed $200 \mathrm{kWh}$ in (G1) and (G2), respectively. This is due to their higher visible light transmittance than other glazing

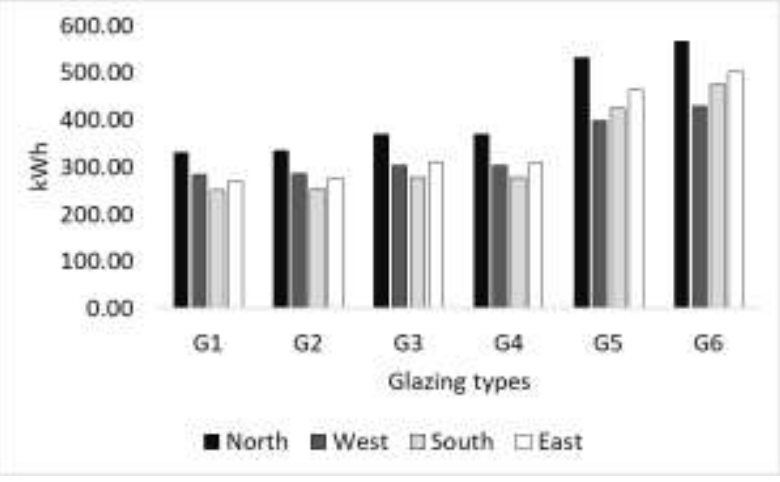

(a) energy consumption types, as well as the building orientation, which allows sunlight to pass through these windows during working hours. (G3), and (G4) have the same results in all building orientations in terms of lighting energy due to their identical visible light transmittance.

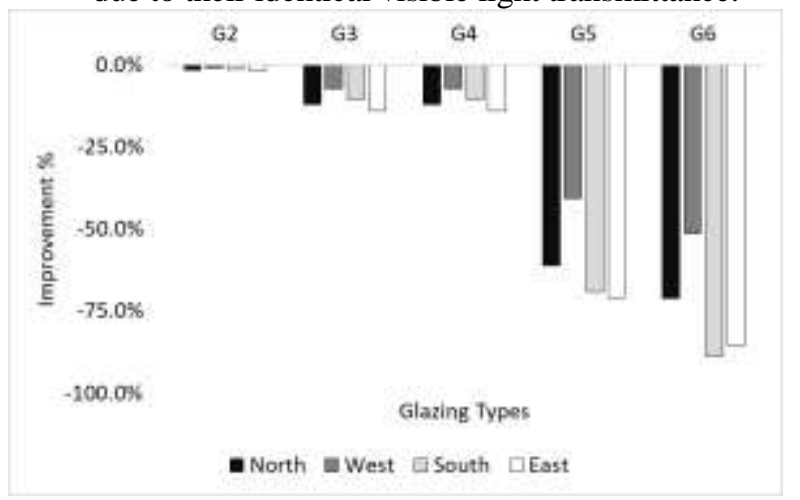

(b) energy savings percentages.

Figure 5. Lighting simulation results for window glazings (WWR=10\%): energy consumption and saving.

When WWR $=10 \%$ was utilized instead of $\mathrm{WWR}=20 \%$, the findings for lighting energy purposes were less favorable. For WWR $=10 \%$, it was discovered that the annual energy required for lighting increased by $71.3 \%, 51.4 \%, 89 \%$, and $85.7 \%$ in the following directions, respectively (north, west, south, and east). Similarly, while utilizing (G5) instead of (G1), the annual energy demand for lighting increased by $61.3 \%, 40.8 \%, 69.1 \%$, and $70.9 \%$ for north, west, south, and east directions, respectively. When compared to (G1), (G3), and (G4) have almost the same impact, raising the annual energy demand for lighting by $7.3 \%$ to $13.9 \%$. In the instance of (G6), the annual energy demand for lighting increased by $113.80 \mathrm{kWh}, 80.14 \mathrm{kWh}$, $135.35 \mathrm{kWh}$, and $123.42 \mathrm{kWh}$ in the north, west,

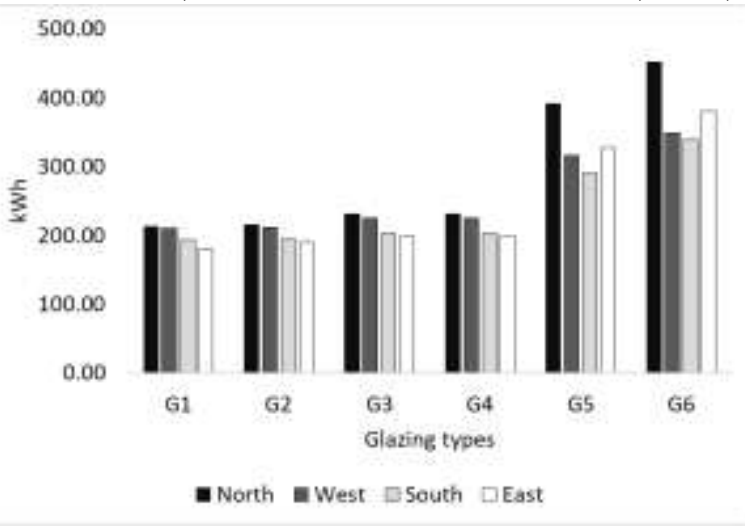

(a) energy consumption south, and east directions, respectively. When utilizing (G1) for the same directions, it increased by $117.12 \mathrm{kWh}, 73.38 \mathrm{kWh}, 57.76 \mathrm{kWh}$, and 90.98 $\mathrm{kWh}$ compared to the same window glazing in case of $\mathrm{WWR}=20 \%$.

In general, when comparing all of the examined glazing types with (G1), it was discovered that the efficacy of the glass in terms of annual energy required for lighting purposes ranged from (G2) to (G6). Furthermore, the annual energy required for lighting is not greater than $565.32 \mathrm{kWh}$, and the largest difference between the worst glazing type (G6) and the standard (G1) is not greater than $238 \mathrm{kWh}$ in all studied directions. Figure 6 shows the result of energy usage for lighting purposes (WWR $=20 \%$ ).

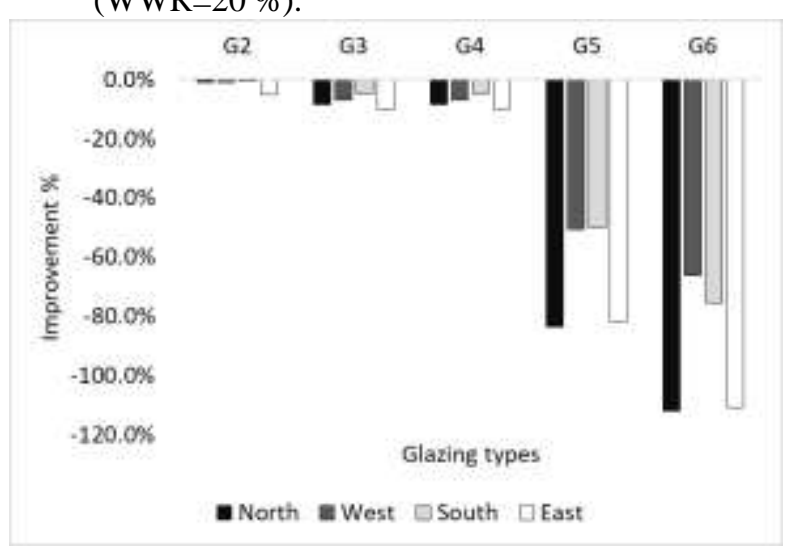

(b) energy savings percentages.

Figure 6. Lighting simulation results for window glazings (WWR=20\%): energy consumption and saving.

\subsection{The effect of the glazing types on total energy}

consumption in buildings.

This study aims to investigate the best glazing for office buildings in Aswan in terms of energy consumption for cooling and lighting by using a standard room and taking into consideration various 
building orientations. The study showed the different performances of the used glazing types. While some glazing types performed well in terms of cooling energy consumption, they performed poorly in terms of lighting energy consumption in the investigated WWR. The other types of glazing showed a completely different performance, as they saved a lot of energy for lighting purposes, while the demand for energy in terms of cooling purposes increased steadily. For example, despite (G6) exhibited its better efficiency in terms of cooling energy needed when compared to other glazing types, (G6) has the lowest performance among the other tested glazing types in terms of energy required for lighting purposes. This is mainly attributed to the visual transmittance of the double-glazed layer (0.92) which is higher than that of nanogel glazing (0.3). While (G6) has the lowest U-value among all glazing types. On the other side, for the WWR $=20 \%$, (G1) saves energy required for lighting purposes by more than $112 \%$ of total energy consumed by (G6) in the northern direction. While it shows the worst performance in terms of energy needed for cooling among all studied cases. Furthermore, (G1) shows the best performance for lighting purposes in all building orientations. In the western direction and $\mathrm{WWR}=20 \%$, it saves about $66.2 \%$ of total energy consumed for lighting compared by (G6). In the southern orientation and WWR $=20 \%$, it saves about
$75.4 \%$ for the same purposes. While the energysaving is $101.5 \%$ in the eastern orientation for the same WWR.

Where WWR $=10 \%$, (G6) decreases the annual energy demand for cooling in the western direction by $22 \%$ when compared to (G1). While also increasing the annual energy required for lighting by $66.2 \%$. Generally, the total amount of energy consumed by (G6) has decreased when compared to other glazing types, even though the annual energy demand for lighting has been increased by a higher rate.

Heating energy consumption was calculated on an annual basis. Thermal characteristics across the hot dry climate are primarily responsible for the low amount of energy required for heating in these locations. As a result, the amount of energy needed for heating might be overlooked when compared to the amount of energy required for cooling and lighting. However, the influence of different types of glazing types on annual energy usage for cooling, heating, and lighting is shown in Figure 7 for both $\mathrm{WWR}=10 \%$ and $\mathrm{WWR}=20 \%$. Where the results show that hot, dry regions require more energy for cooling than they do for lighting, this necessitates the use of glass with a low heat transfer coefficient, such as (G6), while yet allowing for enough natural illumination.

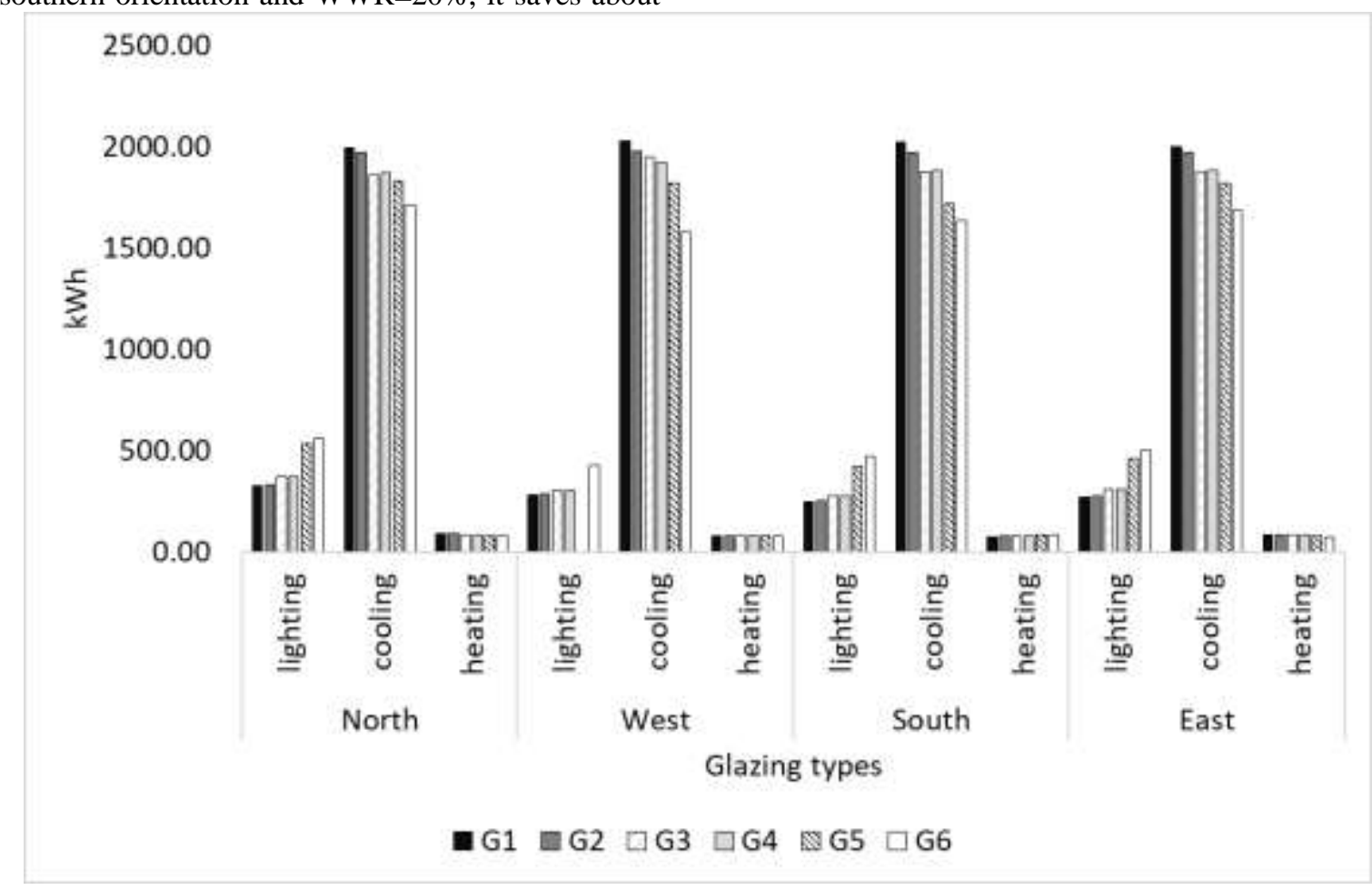

(a) $(\mathrm{WWR}=10 \%)$ 


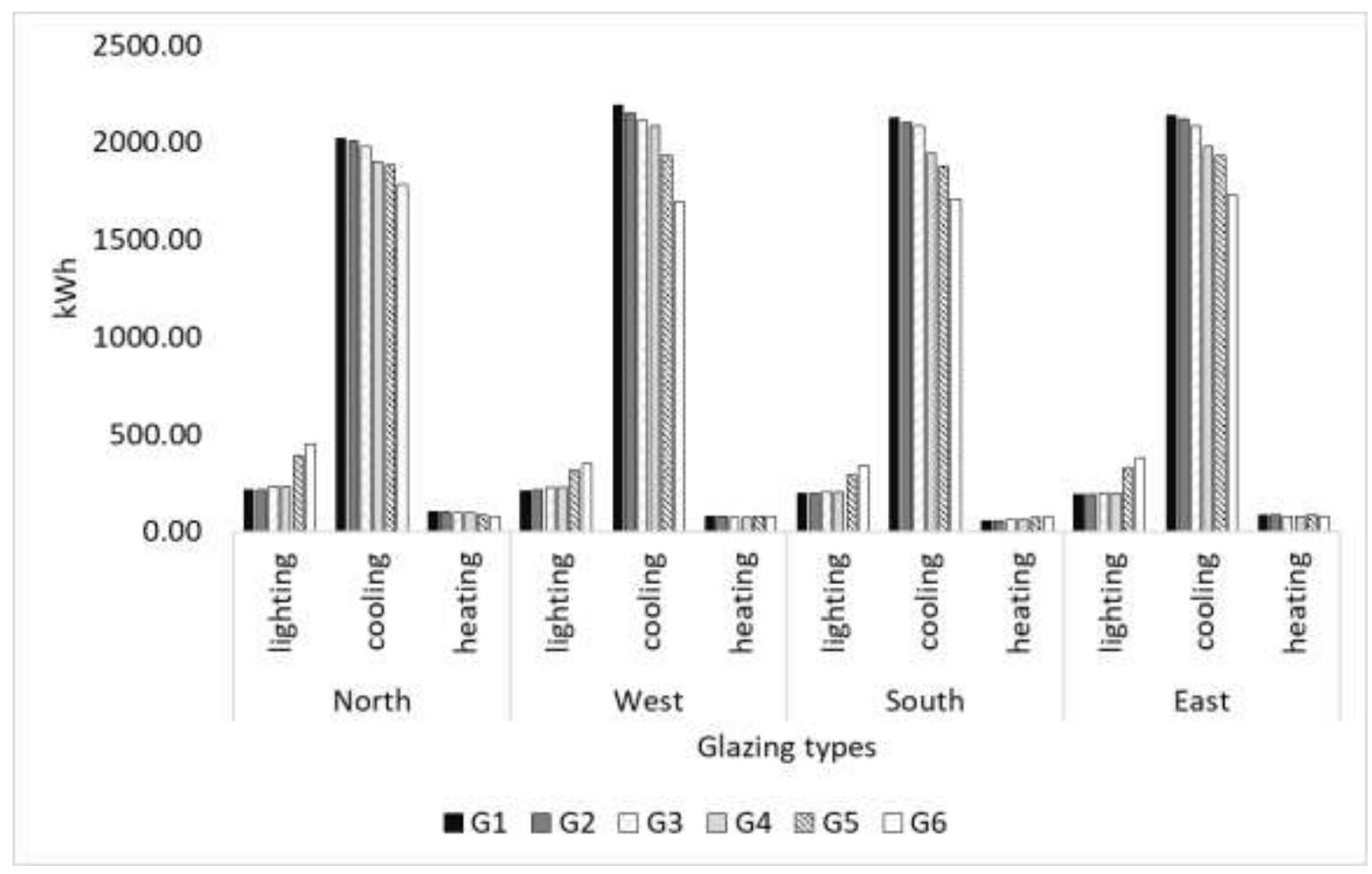

(b) $(\mathrm{WWR}=20 \%)$

Figure 7. Energy consumption for cooling, heating, and lighting considering different building orientations:

$(\mathrm{WWR}=10 \%)$, and $(\mathrm{WWR}=20 \%)$

\subsection{The procedure for selecting the optimum glazing}

types for office buildings.

Choosing the best glazing does not rely just on thermal and optical properties; it is a complicated process that is influenced by a variety of criteria. The Pugh matrix was used in this study to identify the appropriate glazing in Egypt's hot desert areas according to these different criteria. All the investigated criteria were locally weighted based on a questionnaire that was administered to fifty employees in the office buildings of Aswan city. The Pugh matrix, named after its creator Stuart Pugh, is a decision-making tool for comparing competing notions to a fundamental concept. It is based on a set of established, weighted criteria, the comparison of alternatives to a fundamental solution, the multiplication of evaluations with the corresponding weightings, and the subsequent addition of the weighted evaluations. The Pugh Matrix, also known as the Pugh Method, Pugh Analysis, Pugh concept, Pugh controlled convergence or decision-matrix method. The Pugh Matrix's success stems from its simplicity. The tool is not too mathematical and is pretty straightforward to use. However, it has a track record of producing the same results as mathematically intensive methods, although with far less effort. It consists of a table with the following columns: category, criteria, weight, and the investigated alternatives.

The proposed glazing types were studied using numerous criteria derived from three major categories. These include environmental, economic, and technical categories. All generated criteria were weighted using a paper questionnaire based on the office buildings occupants' knowledge of the criteria and their relevant priorities. The occupants' responses were evaluated on a scale of 0 to 5 based on the priority of each criterion. A value of 0 indicates that this criterion is not necessary. A score of one is considered poor, while a score of two is considered fair. A score of 3 is considered average, while a score of 4 is considered good. 5 is an outstanding rating. Figure 8 displays the outcomes of the expert responses for each criterion. 


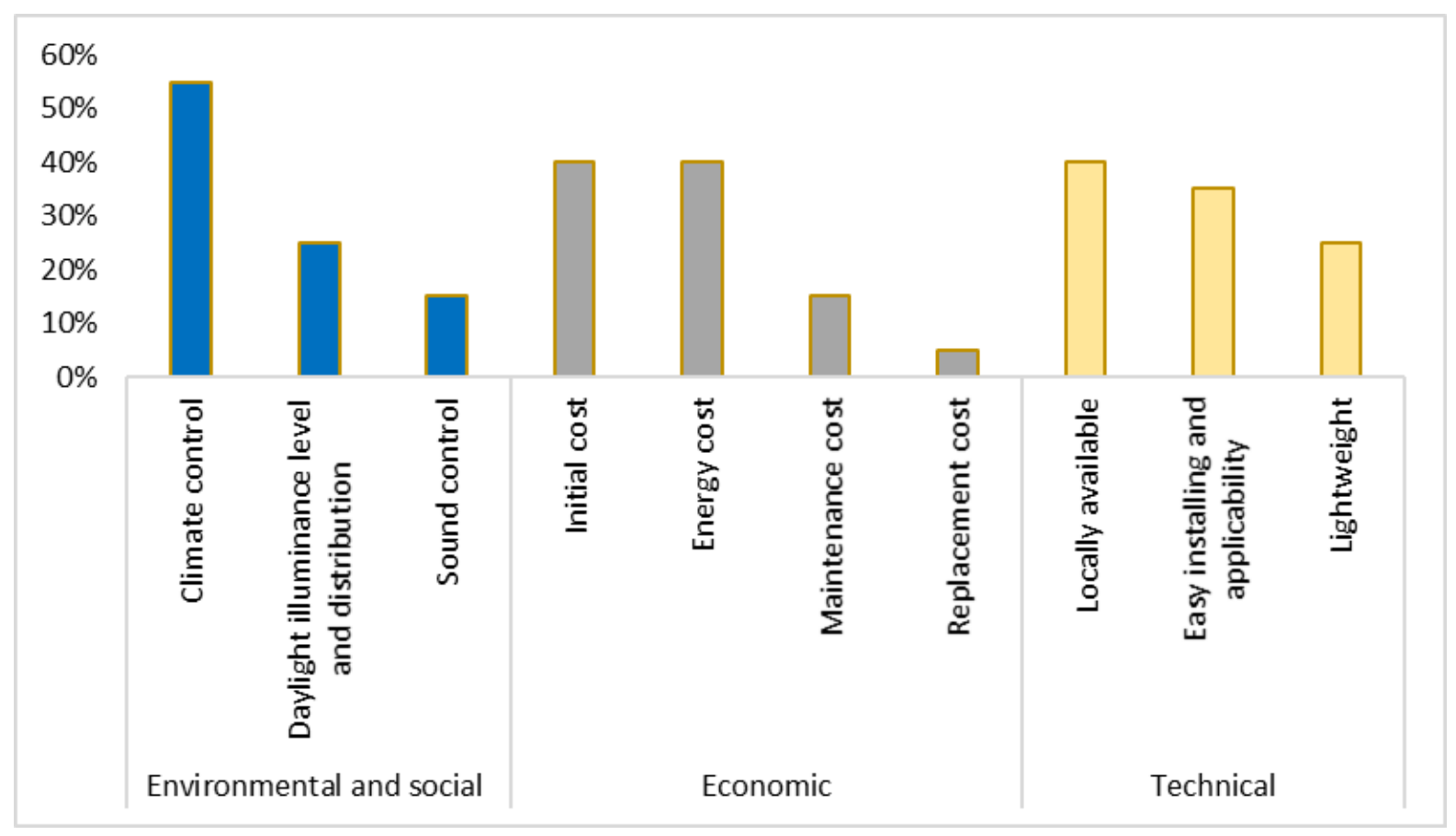

Figure 8. The results of questionnaire according to the employees' responses.

\subsection{Environmental criteria}

\subsubsection{Climate control}

The technological advancements of the twentieth century opened up nearly unlimited possibilities. New glazing techniques, for example, give more control over the building envelope. In addition to its fundamental function of allowing light through the glass, it has now evolved an additional property in response to modern needs for climate control, sound control, and risk control. In this section, climate control will be focused on.

The following are some of the major performance parameters for solar control glass:

1. Solar Heat Gain Coefficient (SHGC).

2. Insulation U Value

3. Shading Coefficient (SC).

According to the International Association of Certified Home Inspectors (IACHI), previous studies have shown that the lower the values of each parameter, the better the performance of the various glass types. If cooling is a primary priority in hot dry climates, windows, and skylights with an SHGC of less than 0.40 are typically recommended. While the recommended average U-values for windows is $2 \mathrm{~W} / \mathrm{m}^{2} \mathrm{~K}$. The reference glazing in this study is $(\mathrm{G} 1)$, which is $3 \mathrm{~mm}$ Clear Glass. As a result, all of the investigated glazing types are more efficient than (G1)[25].

\subsubsection{Daylight illuminance level and distribution}

The fundamental element to improve building energy efficiency is to reduce illuminance demand during daylight hours. Illuminance refers to the amount of light that reaches the surface. It is generally expressed in lux units[26]. Radiance engine simulation in Design-Builder Software is used to simulate daylight illuminance levels. The visible fraction of the light spectrum that passes through a glazing material is referred to as its optical property. It usually varies between $90 \%$ for transparent glass and $10 \%$ for highly reflective coated glazing. The type of glazing, the number of panes, and the presence of coatings that might impact transparency all influence this factor[27]. A high visual transmittance indicates more daylight in an area and, in most cases, lower electric lighting demands.

\subsubsection{Sound control}

The sound reduction will increase with greater glass thickness. This is especially true at lower frequencies. Sound reduction decreases slightly as the glass area increases, but not enough to make a noticeable impact in most architectural glass sizes. In addition to the glass thickness, the rubber gaskets are critical in creating a hermetic seal to the window or door assembly to prevent air leakage and hence sound transmission through the air. As a result, with the same installation characteristics as rubber gaskets, the glass thickness is regarded as a fundamental key to noise reduction. In general, the most common glass thicknesses utilized in soundproof windows are combinations of $4 \mathrm{~mm}$ panes or greater[28].

\subsubsection{Economic criteria}

3.4.2.1. Initial cost 


\section{Vol.42, No.1. January2023}

The initial cost of the chosen glazing is calculated by taking into account the costs of procurement, transportation, and installation (Eq. (1))[29].

$$
I C=P+T+I
$$

where IC is the initial cost; $\mathrm{P}$ is the purchase cost; $\mathrm{T}$ is the transportation cost, and $\mathrm{I}$ is the installation cost. Companies frequently provide information on both purchase and installation costs. The transportation cost for each glazing type takes into account the distance between the manufacturer and the site.

\subsubsection{Energy cost}

The cooling and lighting requirements for each glass type were simulated using Design-Builder (DB) software. The annual cost of energy consumption per unit is always calculated in Egyptian Pounds (EGP) using a commercial rate defined by the Egyptian Ministry of Electricity and Renewable Energy (Table 4).

Table 4. The electricity price for commercial buildings.

\begin{tabular}{ccc}
\hline Bracket & Category $(\mathbf{k W h})$ & Price (EGP) \\
\hline First & $0: 100$ & 0.65 \\
Second & $101: 250$ & 1.2 \\
Third & $251: 600$ & 1.4 \\
Fourth & $601: 1000$ & 1.55 \\
Fifth & more than 1000 & 1.6 \\
\hline
\end{tabular}

\subsubsection{Maintenance cost}

To keep glazing systems operating effectively during their lifespan, annual maintenance costs must be incurred. Cleaning and repairing are both included in the cost of maintenance. As operational expenses, they must be calculated in future values. The annual maintenance cost for glazing systems is $1 \%$ of the purchase cost. This rate was converted to a future value using the following equation (Eq. (2))[29].

$$
M_{f v}=\sum_{t=0}^{n}\left(C l_{t}+R e_{t}\right) \frac{1}{(1+r)^{t}}
$$

where $M_{f v}$ is the cost of maintenance in the future; $\mathrm{Cl}$ denotes cleaning costs, $R e$ denotes repair costs, and $n$ denotes the life cycle period. The number of a year is $t$, and the real interest rate is $r(\%)$.

\subsubsection{Replacement cost}

Several studies have advised that such windows be replaced after 30 years. The reason for this is that after this period, maintenance becomes unprofitable. The costs of the whole replacement stage are almost included in the future value. Following the destruction of glazing systems, a resale for recycling procedure is carried out to generate revenue and lower the overall replacement cost. In any case, the replacement process is on hold until the decision-makers decide to renovate the entire building[30].

\subsubsection{Technical criteria}

\subsubsection{Locally available}

One of the most significant elements that aid the spread of the glazing industry is the availability of raw materials locally. The glazing industry is one of the numerous sectors that can be found in many different countries. However, the creation of new types of glass filled with gases such as air, argon, or nanomaterials, demanded the presence of these nanoparticles locally. These resources may not be readily available, necessitating the purchase of these items on the worldwide market while paying the cost of shipping, which raises the total cost.

\subsubsection{Easy installing and applicability}

Glass production has a long history that returned to about $3500 \mathrm{BC}$, when it is thought that glass was first artificially manufactured in Egypt and Mesopotamia for use as jewels. Since then, methods have progressed from handicraft to high-tech industrial processes, and the variety of glass kinds and uses has increased dramatically. Glass melting necessitates the use of two types of raw materials: various types of sand and recycled glass. These raw ingredients are combined and put into a furnace, where they are melted to produce molten glass at about $1500^{\circ} \mathrm{C}$. The molten glass is then removed from the furnace and formed before being cooled. While the aerogels are one of the lightest solid materials yet discovered. They are made by mixing a polymer with a solvent to make a gel, then removing the liquid and replacing it with air. Aerogels are highly porous and have a very low density. They have a sturdy feel about them. This transparent material is regarded as one of the best available for insulation[31]. In general, Egypt has a long history of glass manufacturing. However, it does not have the same track record when it comes to nanomaterials and their applications in the glass industry.

\subsubsection{Lightweight}

Due to their impact on transportation costs as well as their effect on the potential of being applied, lightweight materials have a considerable impact on the selection process of construction materials. Considering the lightweight for each glazing type, there is no significant difference in terms of lightweight when comparing (G1), and (G2), as opposed to (G3), (G4), (G5), and (G6).

\subsection{The Pugh matrix evaluation results for optimal} glazing type selection 
The values used to evaluate each criterion are listed in (Table 5). The optimum value for each criterion was determined by selecting the minimum or maximum value. While the measuring unit for each criterion was defined. For the environmental category, the U-value $\left(\mathrm{W} / \mathrm{m}^{2}-\mathrm{K}\right)$ is used as an indicator for evaluating the efficiency of climate control. Visible light transmission is considered the main indicator for evaluating the daylight illuminance level. While the used glazing thickness $(\mathrm{mm})$ contributes to a significant impact in terms of sound control. All proposed criteria for the economic category were measured by $\left(\mathrm{EGP} / \mathrm{m}^{2}\right)$. Three criteria make up the technical category. The lightweight is measured in $\left(\mathrm{kg} / \mathrm{m}^{2}\right)$. While other factors such as local availability, ease of installation, and application are evaluated as points. If the glazing type is locally available, the local availability criterion is set to (1). It takes the value (0) if it is not locally available. For the second criterion "ease of installation and application", the proposed glazing was rated according to the widespread of each glazing. Since (G1), and (G2) are the most commonly used glazings, they gained (1) point according to their easier installation compared to other glazing types. Other glazings rated from 0.8 to 0.2 due to their various degrees of ease of installation. Even though it was extensively used in Egypt, the (G1) was regarded the reference glazing. As a result, (G1) has a value of (1) for all criteria. In addition, all suggested glazing types were rated based on the values of (G1). (G1) was used as a reference glazing to be compared to other examined glazing types. By using the Pugh matrix, all other investigated glazing types were compared to the reference glazing (G1). As shown in Table 6, (G6) had the highest score of 3.54 out of all the glazing types evaluated. (G3) and (G4) tied for second place with a score of 1.09. According to the comparison matrix, the poorest glazing type is (G2) with a score of 0.9. In more detail, the substantial superiority of (G6) glass over other types of glass is owing to its high efficiency in terms of the environmental category, where (G6) glass scored 3.28, while none of the other types of glass tested scored more than 0.74 .

Table 5. Results for each criterion across all investigated glazing types

\begin{tabular}{|c|c|c|c|c|c|c|c|c|c|}
\hline Category & Criteria & Units & $\begin{array}{l}\text { Optimum } \\
\text { value }\end{array}$ & G1 & G2 & G3 & G4 & G5 & G6 \\
\hline \multirow{3}{*}{ Environmental } & Climate control & $\mathrm{W} / \mathrm{m}^{2}-\mathrm{K}$ & $\min$ & 5.894 & 5.778 & 2.665 & 2.511 & 2.132 & 0.45 \\
\hline & $\begin{array}{l}\text { Daylight illuminance } \\
\text { level and distribution }\end{array}$ & - & $\max$ & 0.898 & 0.881 & 0.781 & 0.781 & 0.373 & 0.3 \\
\hline & Sound control & $\mathrm{mm}$ & $\max$ & 0.03 & 0.06 & 0.25 & 0.25 & 0.22 & 0.48 \\
\hline \multirow{4}{*}{ Economic } & Initial cost & $\mathrm{EGP} / \mathrm{m}^{2}$ & $\min$ & 1450 & 1570 & 1963 & 2355 & 2826 & 5055 \\
\hline & Energy cost & $\mathrm{EGP} / \mathrm{m}^{2}$ & $\min$ & 1039 & 1019 & 976 & 976 & 929 & 855 \\
\hline & Maintenance cost & $\mathrm{EGP} / \mathrm{m}^{2}$ & $\min$ & 415 & 466 & 674 & 934 & 1193 & 1322 \\
\hline & Replacement cost & $\mathrm{EGP} / \mathrm{m}^{2}$ & $\min$ & 1919 & 3140 & 4536 & 6281 & 8026 & 8900 \\
\hline \multirow{3}{*}{ Technical } & Locally available & points & $\max$ & 1 & 1 & 1 & 1 & 0 & 0 \\
\hline & $\begin{array}{l}\text { Easy installing and } \\
\text { applicability }\end{array}$ & points & $\max$ & 1 & 1 & 0.8 & 0.6 & 0.4 & 0.2 \\
\hline & Lightweight & $\mathrm{kg} / \mathrm{m}^{2}$ & $\min$ & 7.5 & 15 & 27.36 & 30.17 & 30.23 & 30.87 \\
\hline
\end{tabular}

\footnotetext{
* The initial and maintenance costs were provided by a) www.alibaba.com and b) Arab Contractor Company, Egypt.
} 
Vol.42, No.1. January2023

Table 6. Pugh matrix for the selection of the appropriate glazing type

\begin{tabular}{|c|c|c|c|c|c|c|c|c|c|c|c|c|c|c|}
\hline \multirow[b]{2}{*}{ Criteria } & \multirow[b]{2}{*}{ Sub-criteria } & \multirow{2}{*}{$\begin{array}{c}\text { Local } \\
\text { Weight } \\
\%\end{array}$} & \multicolumn{2}{|c|}{ G1 } & \multicolumn{2}{|c|}{ G2 } & \multicolumn{2}{|c|}{ G3 } & \multicolumn{2}{|c|}{ G4 } & \multicolumn{2}{|c|}{ G5 } & \multicolumn{2}{|c|}{ G6 } \\
\hline & & & Rating & $\begin{array}{l}\text { Weight } \\
\text { score }\end{array}$ & Rating & $\begin{array}{c}\text { Weight } \\
\text { score }\end{array}$ & Rating & $\begin{array}{l}\text { Weight } \\
\text { score }\end{array}$ & Rating & $\begin{array}{l}\text { Weight } \\
\text { score }\end{array}$ & Rating & $\begin{array}{l}\text { Weight } \\
\text { score }\end{array}$ & Rating & $\begin{array}{c}\text { Weight } \\
\text { score }\end{array}$ \\
\hline \multirow{4}{*}{ 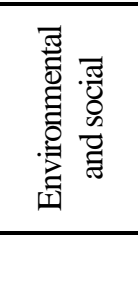 } & Climate control & 55 & 1.00 & 0.55 & 1.02 & 0.56 & 2.21 & 1.22 & 2.35 & 1.29 & 2.76 & 1.52 & 13.10 & 7.21 \\
\hline & $\begin{array}{l}\text { Daylight illuminance } \\
\text { level and distribution }\end{array}$ & 25 & 1.00 & 0.25 & 0.98 & 0.25 & 0.87 & 0.22 & 0.87 & 0.22 & 0.42 & 0.11 & 0.33 & 0.08 \\
\hline & Sound control & 15 & 1.00 & 0.15 & 0.50 & 0.08 & 0.12 & 0.02 & 0.12 & 0.02 & 0.14 & 0.02 & 0.06 & 0.01 \\
\hline & & 45 & & 0.43 & & 0.40 & & 0.65 & & 0.69 & & 0.74 & & 3.28 \\
\hline \multirow{5}{*}{ 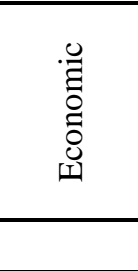 } & Initial cost & 40 & 1.00 & 0.40 & 0.92 & 0.37 & 0.74 & 0.30 & 0.62 & 0.25 & 0.51 & 0.20 & 0.29 & 0.12 \\
\hline & Energy cost & 40 & 1.00 & 0.40 & 1.02 & 0.41 & 1.06 & 0.42 & 1.06 & 0.42 & 1.12 & 0.45 & 1.22 & 0.49 \\
\hline & Maintenance cost & 15 & 1.00 & 0.15 & 0.89 & 0.13 & 0.62 & 0.09 & 0.44 & 0.07 & 0.35 & 0.05 & 0.31 & 0.05 \\
\hline & Replacement cost & 5 & 1.00 & 0.05 & 0.61 & 0.03 & 0.42 & 0.02 & 0.31 & 0.02 & 0.24 & 0.01 & 0.22 & 0.01 \\
\hline & & 35 & & 0.35 & & 0.33 & & 0.29 & & 0.26 & & 0.25 & & 0.23 \\
\hline \multirow{6}{*}{ 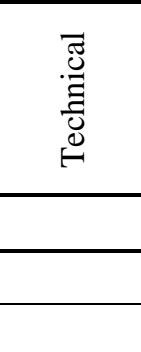 } & Locally available & 40 & 1.00 & 0.40 & 1.00 & 0.40 & 1.00 & 0.40 & 1.00 & 0.40 & 0.00 & 0.00 & 0.00 & 0.00 \\
\hline & $\begin{array}{l}\text { Easy installing and } \\
\text { applicability }\end{array}$ & 35 & 1.00 & 0.35 & 1.00 & 0.35 & 0.80 & 0.28 & 0.60 & 0.21 & 0.40 & 0.14 & 0.20 & 0.07 \\
\hline & Lightweight & 25 & 1.00 & 0.25 & 0.50 & 0.13 & 0.27 & 0.07 & 0.25 & 0.06 & 0.25 & 0.06 & 0.24 & 0.06 \\
\hline & & 20 & & 0.20 & & 0.18 & & 0.15 & & 0.13 & & 0.04 & & 0.03 \\
\hline & Total score & 100 & & 0.98 & & 0.90 & & 1.09 & & 1.09 & & 1.03 & & 3.54 \\
\hline & Rank & & & 4 & & 5 & & 2 & & 2 & & 3 & & 1 \\
\hline
\end{tabular}




\section{CONCLUSIONS}

The research aims to improve the energy efficiency of an office building in Aswan, Egypt, which has a hot, dry climate. A building model was created to evaluate the influence of various window glazing types on the energy consumption for cooling and lighting. The results demonstrated numerically that the suggested glazing type (G6) can significantly lower the energy consumption for cooling in hot dry locations. This efficacy was reduced in the other tested window glazing types due to their high thermal conductivity values, and solar heat gain coefficient (SHGC). On the other hand, (G6) demonstrated the poorest performance among the investigated window glazing types in terms of energy required for lighting due to its low visible light transmittance value. In general, the results revealed that when compared to the energy required for lighting and heating, the energy required for cooling has the greatest impact on the overall energy of buildings in hot and dry regions. Furthermore, when the window to wall ratio $\mathrm{WWR}=10 \%$, (G6) indicated a decrease in total energy ranging from $3.66 \%$ to $12.71 \%$ in all orientations of the building. While (G6) likewise showed the best performance among all glazing types examined when $\mathrm{WWR}=20 \%$. It reduces overall energy consumption by an average of $1.9 \%$ to $14.41 \%$ for all building orientations. Using the Pugh matrix to assist decision-makers, it becomes obvious that (G6) is the best choice provided via this study after analyzing all of the categories and the criteria generated from these categories. G6 exhibited the best score (3.54) compared to the other types of glazing. In this perspective, it is feasible to state that the suggested glazing (G6) with WWR $=10 \%$ considerably reduces overall energy consumption in office buildings located in hot dry climates. However, the work does not address the potential effects of the proposed glazing types on the reduction of ambient temperature in these buildings, although this study shows that cooling requires a significant amount of energy when compared to other energy uses such as lighting and heating. This is a wonderful topic for future research. However, the work's results are restricted to the overall energy consumption evaluated and the data collected using simulation software (Design Builder). To conclude, the energy demand for cooling in hot, dry climates should be prioritized at the early stages of architectural design since it promotes the sustainability concept in these buildings.

\section{REFERENCES}

[1] UNDP, "Sustainable Development Goals Report. Egypt 2030.," 2018.
[2] I. R. E. Agency, "Renewable Energy Outlook Egypt," 2018.

[3] A. Abdelrady, M. H. H. Abdelhafez, and A. Ragab, "Use of insulation based on nanomaterials to improve energy efficiency of residential buildings in a hot desert climate," Sustainability, vol. 13, no. 9, p. 5266, 2021.

[4] A. M. Aly, M. H. Hassn, Y. R. Abdel Rady, and A. T. Mohammed, "The effect of using nano-materials in external openings on energy consumption in hot desert climate," JES. Journal of Engineering Sciences, vol. 48, no. 3, pp. 468-477, 2020.

[5] A. Ragab and A. Abdelrady, "Impact of green roofs on energy demand for cooling in Egyptian buildings," Sustainability, vol. 12, no. 14, p. 5729, 2020.

[6] A. Ragab Abdel Radi, "The Impact of Phase Change Materials on the Buildings Energy Efficiency in the Hot Desert Areas the Annexed Rooms of the Traffic Building in New Aswan City as a Case Study," JES. Journal of Engineering Sciences, vol. 48, no. 2, pp. 302-316, 2020.

[7] M. Alwetaishi, "Impact of glazing to wall ratio in various climatic regions: A case study," Journal of King Saud UniversityEngineering Sciences, vol. 31, no. 1, pp. 618, 2019.

[8] S. Cesari, P. Valdiserri, M. Coccagna, and S. Mazzacane, "Energy savings in hospital patient rooms: The role of windows size and glazing properties," 2018.

[9] Y.-S. Yoon, W.-K. Choi, and M.-H. Sim, "A study on the characteristics of the energy performance in curtain wall buildingFocused on the glazing type, window to wall ratio and internal gains," Journal of the Architectural Institute of Korea Planning \& Design, vol. 29, no. 7, pp. 255-263, 2013.

[10] V. Ž. Leskovar and M. Premrov, "An approach in architectural design of energyefficient timber buildings with a focus on the optimal glazing size in the southoriented façade," Energy and Buildings, vol. 43, no. 12, pp. 3410-3418, 2011.

[11] W. Hee et al., "The role of window glazing on daylighting and energy saving in buildings," Renewable and Sustainable Energy Reviews, vol. 42, pp. 323-343, 2015.

[12] N. Y. Azmy and R. E. Ashmawy, "Effect of the Window Position in the Building Envelope on Energy Consumption," Int. J. Eng. Technol, vol. 7, no. 3, p. 1861, 2018.

[13] M. Ciampi, F. Fantozzi, F. Leccese, and G. Tuoni, "On the optimization of building envelope thermal performance: Multilayered wall design to minimize heating and 
Cooling plant intervention in the case of time varying external temperature fields," Civil Engineering and Environmental Systems, vol. 20, no. 4, pp. 231-254, 2003.

[14] D. Gossard, B. Lartigue, and F. Thellier, "Multi-objective optimization of a building envelope for thermal performance using genetic algorithms and artificial neural network," Energy and Buildings, vol. 67, pp. 253-260, 2013.

[15] S. Korniyenko, "Evaluation of thermal performance of residential building envelope," Procedia Engineering, vol. 117, pp. 191-196, 2015.

[16] N. Mendes, G. H. Oliveira, and H. X. De Araújo, "Building thermal performance analysis by using matlab/simulink," in Seventh International IBPSA Conference, Rio de Janeiro, Brazil, 2001: Citeseer, pp. 473-480.

[17] A. M. Papadopoulos, "Forty years of regulations on the thermal performance of the building envelope in Europe: Achievements, perspectives and challenges," Energy and Buildings, vol. 127, pp. 942-952, 2016.

[18] C. D. Pereira and E. Ghisi, "The influence of the envelope on the thermal performance of ventilated and occupied houses," Energy and buildings, vol. 43, no. 12, pp. 33913399, 2011.

[19] T. Ihara, T. Gao, S. Grynning, B. P. Jelle, and A. Gustavsen, "Aerogel granulate glazing facades and their application potential from an energy saving perspective," Applied Energy, vol. 142, pp. 179-191, 2015.

[20] A. Rashwan, O. Farag, and W. S. Moustafa, "Energy performance analysis of integrating building envelopes with nanomaterials," International Journal of Sustainable Built Environment, vol. 2, no. 2, pp. 209-223, 2013.

[21] M. A. Mujeebu, N. Ashraf, and A. Alsuwayigh, "Energy performance and economic viability of nano aerogel glazing and nano vacuum insulation panel in multistory office building," Energy, vol. 113, pp. 949-956, 2016.

[22] M. A. Mujeebu, N. Ashraf, and A. H. Alsuwayigh, "Effect of nano vacuum insulation panel and nanogel glazing on the energy performance of office building," Applied energy, vol. 173, pp. 141-151, 2016.

[23] C. Marino, A. Nucara, and M. Pietrafesa, "Does window-to-wall ratio have a significant effect on the energy consumption of buildings? A parametric analysis in
Italian climate conditions," Journal of Building Engineering, vol. 13, pp. 169-183, 2017.

[24] Q. Yang, M. Liu, C. Shu, D. Mmereki, U. Hossain, and X. Zhan, "Impact analysis of window-wall ratio on heating and cooling energy consumption of residential buildings in hot summer and cold winter zone in China," Journal of Engineering, vol. 2015, 2015.

[25] J. L. Aguilar-Santana, H. Jarimi, M. Velasco-Carrasco, and S. Riffat, "Review on window-glazing technologies and future prospects," International Journal of LowCarbon Technologies, vol. 15, no. 1, pp. 112-120, 2020.

[26] P. R. Michael, D. E. Johnston, and W. Moreno, "A conversion guide: solar irradiance and lux illuminance," Journal of Measurements in Engineering, vol. 8, no. 4, pp. 153-166, 2020.

[27] E. Cuce and S. B. Riffat, "A state-of-the-art review on innovative glazing technologies," Renewable and sustainable energy reviews, vol. 41, pp. 695-714, 2015.

[28] E. M. Strobach, "Optically transparent, thermally insulating and soundproofing (OTTIS) aerogel for high-efficiency window applications," Massachusetts Institute of Technology, 2020.

[29] Y. O. Elkhayat, M. G. Ibrahim, K. Tokimatsu, and A. A. M. Ali, "Multi-criteria selection of high-performance glazing systems: A case study of an office building in New Cairo, Egypt," Journal of Building Engineering, vol. 32, p. 101466, 2020.

[30] Y. O. Elkhayat, M. G. Ibrahim, K. Tokimatsu, and A. A. M. Ali, "Life cycle cost analysis on three high-performance glazing systems for an office building in New Cairo, Egypt," Architectural Engineering and Design Management, vol. 17, no. 1-2, pp. 131-145, 2021.

[31] Y. Osada, J. Ping Gong, and Y. Tanaka, "Polymer gels," Journal of Macromolecular Science, Part C: Polymer Reviews, vol. 44, no. 1, pp. 87-112, 2004. 


\section{التحقيق في تأثير أنواع الزجاج المختلفة على أداء الطاقة في المناطق الحارة الجافة}

$$
\text { ملخص البحث }
$$

تبحث هذه الدراسة في تأثير عدة أنواع من الزجاج المختلفة ذات التوجهات المختلفة للنافذة مع نسبة النافذة الي الجدار (10)

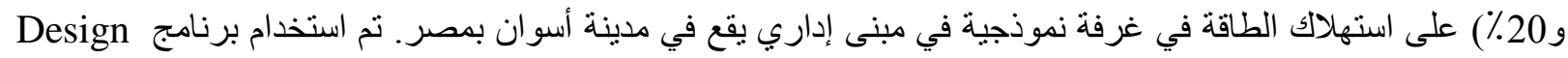

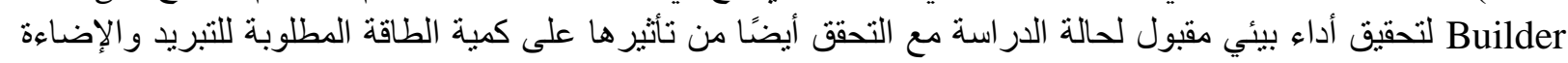

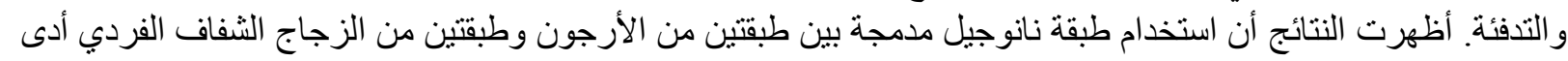

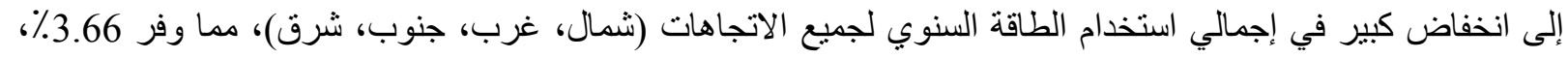

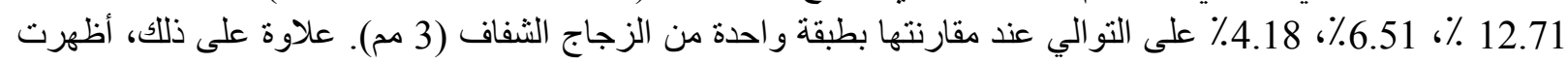

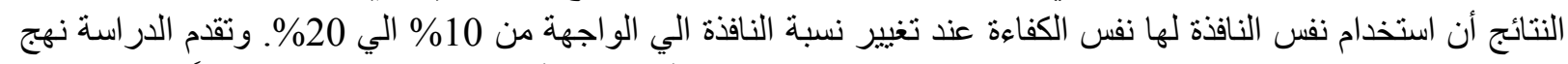

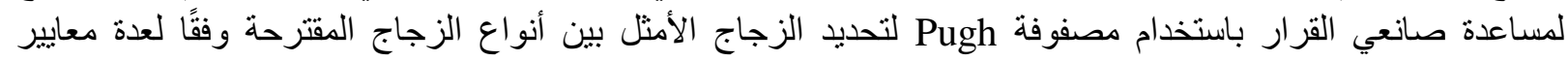

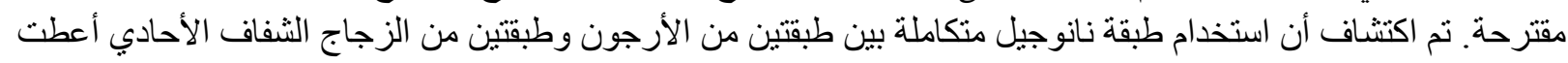

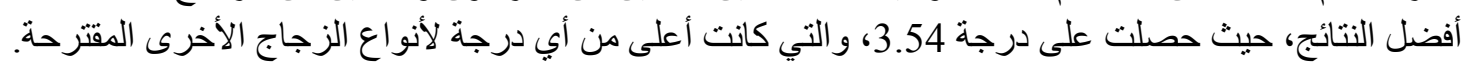

الكلمات المرجعية: كفاءة الطاقة، زجاج نانوي، اتجاهات المباني، نسبة النافذة الي الواجهة، مصفوفة Pugh 